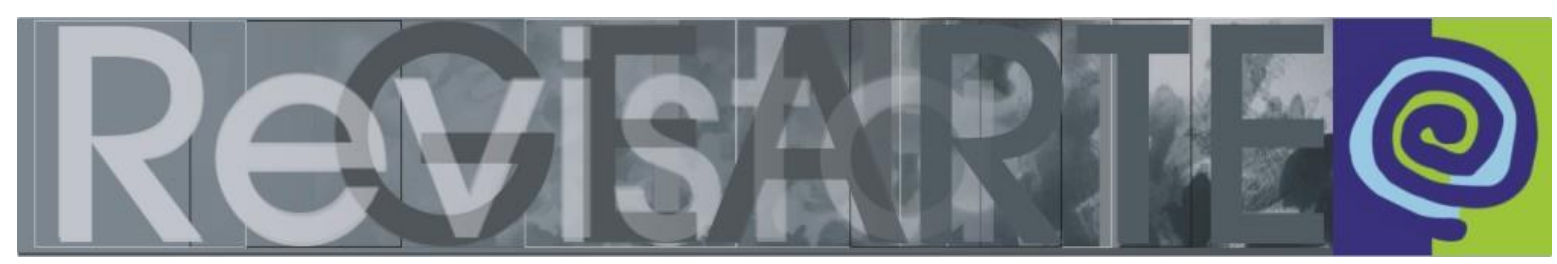

Volume 1, Número 2, Agosto/2014, ISSN 2357-9854

\title{
Por Poéticas no Ensino das Artes: uma sintomatologia
}

\author{
Paola Basso Menna Barreto Gomes Zordan (UFRGS - Brasil)
}

\begin{abstract}
RESUMO
Seguindo à questão colocada desde Nietzsche, "como alguém se torna o que é", mostra-se como grandes agrupamentos discursivos tornam o ensino de artes o que ele é, sendo esse "ser" sempre provisório, sintomatologia de determinados tempos e de conjuntos de textos. Esses dão corpo para constituição de modos de pensar o que vem a ser a arte e seu ensino nas visões expressivistas, semiológicas, estéticas e culturalistas pós-estruturalistas. Partindo de autores e títulos axiais para esses paradigmas, tais discursos são descritos como sintomas no ensino das artes. Menciona-se textos de pesquisadores atuais a fim de explicitar como diferentes abordagens coadunam para mostrar a força do que se configura como uma poética na pesquisa em torno do ensino das artes. Embora sustentados por estudos de diversas perspectivas teóricas, há convergências que observam a afirmação da poiesis inerente à prática pedagógica artística.
\end{abstract}

PALAVRAS CHAVE

poética; discurso; ensino; artes; sintoma.

\section{ABSTRACT}

Following Nietzsche's question, "how one becomes what one is", it shows how large discursive clusters make teaching art what it is, and being this "is" always ephemeral, symptomatology of a time and sets of texts. These give a body to consist ways of thinking that comes to art and its teaching on the expressivists views, semiological, aesthetic and poststructuralism culturalists. Starting from axial authors and titles for these paradigms, such speeches are described as symptoms in arts education. Texts of modern researchers are mentioned to explain how different approaches are consistent to show the strength that constitutes as a poetic research on teaching art. Although supported by studies of different theoretical perspectives, there are convergences that observe the poiesis affirmation inherent to artistic pedagogical practice.

\section{KEYWORDS}

poetic; speech; education; arts; symptom.

Junto à revisão de textos, documentos escolares e práticas institucionais, apresenta-se uma sintomatologia entre as artes ditas "contemporâneas" 1 , a vida nas escolas e a produção acadêmica. O que se propõe encontra ressonâncias em pesquisadores da área escolhidos em função de sua presença tanto em artigos como nos anais específicos da Educação e Arte e Ensino das Artes Visuais, compreendendo as edições entre 2008 e 2013 dos encontros anuais da Associação Nacional de Pesquisa em Artes Plásticas (ANPAP) e Associação Nacional de Pesquisa e Pósgraduação em Educação (ANPED) e demais publicações desde 2006 nessa área de

\footnotetext{
${ }^{1}$ Questiono a nomenclatura "contemporânea" para a produção artística dos tempos atuais, visto o termo "contemporâneo" designar coordenadas espaço-temporais relativas que não expressam a intempestividade do que é inerente tanto aos aspectos poéticos quanto estéticos de um objeto ou proposta tomado como arte.
} 
pesquisa. O presente texto não faz um estado da arte pormenorizado dessa produção e sim dialoga com linhas de pensamento diversificadas que convergem em determinados aspectos do que pode ser defendido como poéticas no ensino de artes. A poética, ao se "pôr" em tempos e espaços, difere da estética, concebida como "sensação, sensibilidade, percepção pelos sentidos ou conhecimento sensívelsensorial" (HERMANN, 2008, p.18). A razão epistêmica dos discursos que fundam as artes enquanto campo de conhecimento têm bases na estética iluminista, ao passo que a poética passa a ser reinventada com a crítica contemporânea, no contexto dos "croquis dos costumes" do que se designava "vida moderna" (BAUDELAIRE, 2010, p.18). Seguindo a questão colocada desde Nietzsche, "como alguém se torna o que é" (1995, p. 48), mostra-se como grandes agrupamentos discursivos tornam o ensino de artes o que ele é, sendo esse "ser" sempre provisório, sintomatologia de determinados tempos e de conjuntos de textos (FOUCAULT, 1995, p. 71-77).

\section{Confluências discursivas}

Ao primar pela "formação de uma cidadania", como os planos políticos pedagógicos das escolas reiteram, observamos como as bases epistemológicas do campo educacional se distanciam da maior parte das "racionalidades" (HERNÁNDEZ, 2000, p. 43-46) ligadas ao Ensino de Arte, à Educação Artística e/ou suas outras designações. Antes das atuais práticas em prol da poética, tais razões tendem a ser pensadas sobre concepções estéticas, de base filosófica, ao invés de científicas. Fazendo uma retomada de discursos que se sobressaem após as práticas de Franz Cizék, professor que criou, no início do século XX, o primeiro curso de artes com teor pedagógico (SMITH, 1985), procura-se compreender o que hoje, passado um século, circula no campo. No âmbito da pesquisa realizada na área de artes e educação atual, surgem novas razões para fundamentar o Ensino da Arte, as quais se distanciam das antigas acepções, ainda que em parte as retome. Ao contrapor tais discursos com o cotidiano das escolas públicas é possível reafirmar descompassos entre a epistemologia da pesquisa em artes e a prática em sala de aula. Essa constatação advém da atuação em aulas e oficinas de arte junto a propostas de modificação de ambientes escolares promovendo a estética relacional (BOURRIAUD, 2009) em projetos de ensino de Artes Visuais. A breve análise aqui apresentada justifica ações que exprimem um trabalho pedagógico poético, que concebe a arte como interação, 
implicando a participação do público em propostas abertas (ibidem, p. 62) advindas de projetos com autoria. Esses vêm acontecendo na convergência tanto de discursos educacionais como dos advindos de movimentos artísticos. São encontros entre áreas diferentes que trazem uma mistura de conceitos, com ênfase no funcionamento de grupos e práticas que podem ser tratadas como poéticas no Ensino da Arte.

Seja em discursos inspirados pela fenomenologia do espírito de Bachelard, como os encontrados nos textos de Sandra Richter (2012; 2004), que atentam para a importância da dimensão poética e da plasticidade, seja nos que bebem das teorias críticas e pós-críticas para problematizar a estética, diversos enunciados convergem para autorizar poéticas em projetos e propostas de ensino. Tais teorizações podem ser detectadas na produção de Marcelo Andrade Pereira (2008) e no que se nomeia "política do sensível" nas pesquisas de Cynthia Farina (2012a). Insinuações poéticas também são advindas de pesquisas culturalistas, como as de cunho "narrativo" com Irene Tourinho e Raimundo Martins (2006), na queer theory e nos estudos do cotidiano (VICTORIO FILHO, 2012). No que Hernández (2013) formula como pesquisa baseada em artes, implicada no construcionismo social do que emerge, apresentado por Marilda Oliveira (2013) como Investigação Baseada nas Artes (IBA), assim como a A/r/tografia (DIAS, 2013), situam-se métodos menos "teóricos" e mais próximos dos processos criativos. A partir dessas referências podemos afirmar proposições poéticas para o ensino da área de pesquisa em questão. Nessas linhas de pensamento há uma recorrência, direta ou indireta, ao conceito de experiência tal como explicado por Larrosa a partir de Walter Benjamin (2002, p. 25), perspectiva que somente após o pensamento de Nietzsche e, posteriormente, com a estética da existência extraída dos estudos de Foucault, pode se constituir. Acrescento, também, a tese de Marly Meira (2003), na qual a reflexão sobre o sentido do sensível conduz, via digressão estética, a uma proposta poética para o ensino das artes.

No âmbito das Artes Visuais, o termo poética vem expressar o devir dos processos de criação, envolvendo desde pesquisa de fontes, elaboração de arquivos, técnicas, métodos, materiais, assim como a relação com textos e, por vezes, conceitos filosóficos. Advém da Poética de Aristóteles de Estagira (2011) na medida em que o traçado de projetos poéticos envolve tratamento de determinados elementos a fim de se obter os efeitos estéticos almejados dentro de gêneros específicos de ação. 
Entretanto, o que nesse âmbito se nomeia poética extrapola as definições aristotélicas que compreendem a poesia como estímulo emotivo, ainda que não se aparte de sua gênese mimética e as implicações da mimesis no desenvolvimento de estilos, tanto na caracterização de personagens (como apresentado no curso de Aristóteles) quanto nas inflexões literárias e visuais estudadas ao longo da história.

Uma amostragem sintomática tende a definir o que concebemos como possível para a pesquisa em artes e o que, a partir de determinadas e provisórias convicções, criou modos de se pensar o ensino da arte. Sendo o sintoma uma alteração de um "funcionamento normal" de um órgão ou organismo, algo sentido por um corpo, ao modo de Foucault (1995), estudar tais signos contingentes permite que possamos enxergar, quando não "tratar" aquilo que desorganiza modos já estabelecidos de pensarmos um campo/corpo. Aqui, o sintoma vem dar conta das quebras ocorridas nos discursos e práticas instituídas, no caso dessa breve análise do corpo de textos aqui referendado, organizado via validação da própria produção acadêmica dentro de um campo de conhecimentos. A fim de tornar inteligível as ampliações e aberturas implicadas nas múltiplas possibilidades de se conceituar e definir a arte, partiremos de seu caráter estético e (po)ético fazendo uma síntese de suas características ao longo das razões, historicamente circunscritas, pelas quais se ensina arte.

Considerando a escola de Cizék o marco do que hoje vem a ser o ensino de artes com propostas pedagógicas direcionadas para a infância e juventude, podemos situar ao longo do século XX, três grandes agrupamentos teóricos para compreender o que fissura discursos e procedimentos educativos: a "livre-expressão", a "leitura de imagens" e a "cultura visual". Esses agrupamentos permitem a observação de produções textuais e discursivas sintomáticas no que tange ao assumido como prática em sala de aula, embasando apreensões diferentes do que se julga arte, fruição estética e criação poética. De modo algum uma concepção ultrapassa a outra, mesmo quando situadas numa sucessão temporal, sendo sua breve explicitação necessária para delinearmos o agrupamento que emerge na segunda década do século XXI.

Expressão plástica e experimentação formal são chaves para se dizer o que fissurou a concepção de arte que vinham sendo definida desde o Barroco. Não envolve pesquisas tal como hoje as concebemos e sim movimentos artísticos, obras e práticas sociais que disseminam, via ações de determinados intelectuais, um novo 
modo de se pensar e ensinar as artes. Por ser um discurso que envolve crítica social, o desenvolvimento da psicologia como campo de estudo, o inédito interesse pela arte das crianças e o olhar para povos que não os europeus, exprime as contundentes rupturas da arte moderna no início do século XX. Há uma grande transformação de meios e materiais considerados próprios para arte e artes ditas "menores" passam a ter validade dentro do sistema de produção de obras. A arte pode, então, ser feita com fins pedagógicos, terapêuticos e mesmo como passatempo. Os estudos da forma são referências importantes (ARNHEIM, 1980) e as experimentações da escola Bauhaus mudam o modelo de cursos superiores de artes. O ensino não formal, em especial as Escolinhas de Arte, afirma uma educação pela arte não submissa às disciplinas técnicas dos currículos escolares. Suas formulações surgem com as obras de John Dewey e se alastram com o livro de Herbert Read, Education through art, traduzido como Educação pela Arte (1982). Destaco a negação do uso de modelos, as críticas às cópias e outras atividades exclusivamente técnicas como a contribuição desse pensamento para o Ensino da Arte, mesmo quando pesquisados por autores oriundos da psicologia, como Lowenfeld e Brittain (1977). Revogando o privilégio da "criatividade", em especial na obra de Fayga Ostrower $(1983,1986)$, esse agrupamento discursivo permite a instituição de um ensino de artes não formal e a proliferação de debates intelectuais sobre seus métodos na escola formal e na formação acadêmica. A maior parte desses textos são ensaísticos e se embasam nas experiências pessoais dos autores em ateliês, salas de aula e oficinas. Podemos situar essa produção bibliográfica no âmbito de intelectuais liberais e críticos de atuação não estritamente acadêmica.

Cognição, etapas para compreensão e semióticas balizam agrupamentos de literatura que se apropriam de estudos específicos da arte no campo educacional, o qual começa a se instituir academicamente desde os anos 1960, ganhando, no Brasil, maiores dimensões nas décadas de 1980 e 1990. Como sintoma de uma civilização que passa a se compreender como "de imagens", esse tipo de produção reflete a transição das artes antes ditas "plásticas" para as "visuais". O que temos hoje são miríades de textos que tratam de "leitura estética" ou "leitura de imagens" com linhas paradigmáticas que remontam ao estruturalismo e ao construtivismo, trazendo acepções cognitivistas sobre a fruição de imagens, na maior parte dos casos extraídas da arte oficialmente legitimada, como por exemplo, as da pesquisa de Michael 
Parsons (1992). Pensando o ensino de artes não apenas como experimentação, visto a liberdade proposta pelo paradigma anterior ter sido diagnosticada num laissez-faire sem nenhuma proposição pedagógica pensada, essas acepções permitem inserir a apreciação de obras como também um elemento chave, tão importante quanto a criação e a expressão individual. Ao introduzir a acepção de apreciar obras e o estudo de contextos no ensino de artes, as pesquisas de Ana Mae Barbosa passam a influenciar os estudiosos a deterem sua atenção nas imagens, sendo as pesquisas de Analice Dutra Pillar $(1996,1998,2001)$ uma importante referência.

Embora possamos sintetizar essa gama de estudos em torno da arte formalista e datada em sua nomenclatura modernista, por vezes apresentando problemas de classificação quanto ao que vem a ser arte, o termo "apreciação" carrega conotações que remetem à obra enquanto produto submisso ao juízo estético tradicional (ser ou não arte) e algumas vezes a ordens mercadológicas. O tipo de obra é o ponto criticado por pesquisadores de âmbito culturalista no que tange a esses estudos, sendo que tal crítica cria um debate relevante, sem o qual o conceito de curadoria não teria migrado para questões de ensino.

Destaco como principal contribuição dessas produções a defesa da implicação das artes como área de conhecimento legitimada academicamente e a defesa da importância desse tipo de ensino para o desenvolvimento intelectual, como atestam os estudos de Abigail Housen (1992), Howard Gardner e outros. Os procedimentos desse tipo de pesquisa geralmente possuem um grupo focal que corrobora hipóteses quanto ao entendimento das obras, envolvendo a fala e a decifração de determinados códigos presentes nas imagens apreciadas. Ainda que, para fins metodológicos, se classifique níveis de compreensão do conteúdo de uma imagem, Maria Helena Rossi, pesquisadora nessa linha, autora de Imagens que falam (2003) vem questionando o que vem a ser uma verdade sobre a arte, a palavra definitiva sobre apreciação e mesmo a pertinência dos modos como pensamos e operamos a leitura de imagens, mais precisamente a mediação (ROSSI, 2010). Mediar obras pauta as problematizações de Miriam Celeste Martins (2006, 2007, 2012), já com atravessamento do pensamento de Deleuze no campo de Ensino de Artes, o que implica questionar o próprio conceito de leitura. Todavia, a concepção de "leitura" de obras de arte não desaparece facilmente, mesmo quando novos enfoques vão sendo 
produzidos, engendrando as inevitáveis traições de sentido que acontecem ao tomarmos a linguagem como elemento bruto de análise.

Fragmentações pós-modernas e não exatamente rupturas acontecem quando múltiplos discursos sobrepostos criam concepções polifônicas, voltadas para linguagens nem sempre legíveis, que se exprimem em mosaicos textuais. Distinguir imagens visualizáveis e linguagem não é uma tarefa simples e, dentro do âmbito da pesquisa, talvez seja impossível, visto jamais podermos abrir mão das palavras. No entanto, enquanto os estudos de cunho semanticista se ocupam na intelecção dessas imagens em sua articulação com enunciados lógicos, a visão, assim como o belo, a perfeição, numa perspectiva culturalista são construções contingentes a tempos e espaços específicos. O axioma advindo dos Cultural Studies permite dizer que imagens visuais, assim como palavras, definem a criação de modos de vida, determinando quem somos, nossas identidades e como vemos os outros. Ao ensinarem e produzirem efeitos, as imagens são objeto de outro tipo de estudo, o qual não recai sobre sua apreensão cognitiva e sim sobre os sistemas de representação a elas inerentes. Ainda que tal assertiva tenha bases no estruturalismo, que pensa a sociedade juntamente com as estruturas da língua, interessa, nesse agrupamento de produções, compreender como se constituem as imagens, sua implicação social e política e como delimitam identidades de raça, gênero, classe, nacionalidade. Nesse âmbito as pesquisas muitas vezes escapam das áreas artísticas, sendo esse agrupamento discursivo disseminado nas pesquisas da Educação em geral. Em razão de sua abrangência e atualidade opto por não citar nenhum pesquisador em especial para não se omitir outros de igual importância.

Essas acepções extrapolam os fatores meramente linguísticos, pois englobam o corpo e outros signos, artefatos diversificados, documentos e textos nem sempre verbais. No pós-estruturalismo a forma não se aparta da linguagem, mas com Foucault (1996) ela configura as linhas visíveis e enunciáveis, nunca completamente formadas, do que chamamos dispositivo. Esse conceito permite que se pense a cultura e as instituições nunca apartadas dos discursos que dispõem modos de vida. Ao conceber as instituições junto às visibilidades que fazem circular os discursos que as sustentam é preciso pesquisar formas de poder que fazem valer determinadas imagens. Diferentes instituições engendram múltiplas formas de visibilidade e enunciação, 
dando a ver as condições de emergência do que venha a ser "verdadeiro", sendo a pesquisa nesse âmbito uma investigação discursiva, geralmente oriunda de observações participantes, com vistas a compreender como uma verdade se forma. O que se sente e o que se pensa não são algo dado, que simplesmente "está aí". Há que se discernir o que compreendemos, o sentido das palavras, as razões da educação, o que são os compromissos assumidos com a Terra, com os outros e como se conduzir (ethos/ética) no planeta, de modo a sermos gentis com todas as formas de vida, inclusive as não formadas ainda, que permeiam aquilo que cultivamos e cultuamos (cultura).

A contribuição dessa paradigmática, de síntese mais complexa que as anteriores, se dá pela compreensão da arte em âmbitos mais amplos. As construções modernistas que diferenciavam obras de arte e artesanato, alta e baixa cultura, são questionadas, sendo todo artefato cultural, oriundo de qualquer povo e lugar do planeta, incluindo a arte dos "loucos", interesse de estudo. A estética que fundamenta suas concepções de arte é aberta a produções dos mais diversificados contextos, e não há uma distinção entre o que é ou não é arte senão dentro de uma análise pormenorizada de um dispositivo. Não há como pesquisar imagens sem contextualizar as condições em que emergem e junto a que discursos se colocam, sendo as imagens, em especial as visuais, tratadas nas devidas relações que elas possuem com o tema desenvolvido. O sintoma, nesse tipo de pesquisa atualmente em voga, é tomar as imagens como meras ilustrações para corroborar assertivas sobre o que a própria cultura, sem pesquisa, nos mostra. Imagens são reflexos, não podemos refletir nada sobre elas além daquilo que elas mesmas refletem. Onde há reflexão não se pensa (DELEUZE e GUATTARI, 1992, p. 14). Pensar é romper com o significado cristalizado sobre as coisas e criar algo onde as forças são assignificantes.

Problematizações em torno dos signos mostram que só há sintomas com a detecção de signos que desestabilizam os sistemas que esperávamos encontrar. Uma sintomatologia requer significações mais ou menos formadas em relação a determinado campo ou corpo, no caso dessa análise, corpos conceituais que constituem agrupamentos de produção textual. O que aqui demonstro, embora não tenha um corpo definido e nem mesmo um agrupamento conceitualmente coeso no discurso que tangencia o Ensino de Arte, é apenas um sintoma que tende para um 
devir poético. Circunscreve-se o ensino e não a educação porque é em relação a processos de significação, tradução e forças assignificantes que essa análise se ocupa, deixando de lado as práticas civilizatórias, domesticadoras, adocilizadoras e outros modos de assujeitamento que o educar implica. Mesmo que, de algum modo, tais discursos reverberem em práticas escolares, os sintomas aqui tratados vêm responder a certos excessos em torno da insistência de se tratar da experiência estética, seja em textos fundamentados, em discursos empíricos ou como palavrachave para se chegar ao poético. O risco é sobrepor esses termos, poético e estético, nos chavões salvacionistas em torno da educação com arte, pela arte e da arte. O que atentamos diz respeito à eleição da "crença na relação direta da arte com os 'espíritos sensíveis", crença que "defende uma imaginada 'educação estética' e outras mitificações da arte", todas essas calcadas sobre a ideia de que haja "uma 'estética legítima' e ensinável" (VICTORIO FILHO, 2008, p.10-11). O problema do que é legítimo, do que se torna ensinável, redunda nas questões ontológicas da própria produção artística e do que seja ou não seja arte, sendo uma definição aquilo que os discursos entre arte e educação elegem como os "conteúdos" a serem trabalhados no espaço legado às artes.

Vivemos uma arte que faz circular concepções de que as obras podem ser inacabadas, abertas, propositivas. Um discurso de "pós-produção" mostra o quanto as teorias da forma dão espaço ao relacional, baseado no diálogo e na prática social. Se há estética, essa configura a "produção de uma sociabilidade específica" (BOURRIAUD, 2009, p. 22), sendo que a arte "converte-se num conjunto de tarefas realizadas ao lado ou sob o sistema" (idem, p. 51). Desde a própria noção de antiarte e vida como arte, presentes em movimentos como o Dadaísmo e o Fluxus, mais cabe pensar as funções do que vem e pode ser arte do que as formas de arte canonicamente postuladas. Pensar as confluências e acima de tudo os desvios do que, no campo educacional, transcorrem como o que se ensina em artes, é o que permite, segundo Marcos Villela, "pautarmos nossa discussão pelas formas de operação, uso, experiência e entendimento da obra de arte, procurando desviar a resposta da captura reducionista da definição, da classificação ou do julgamento" (PEREIRA, 2012). Na esteira da instituição do que aceitamos como "verdade" o que vem a ser importante e necessário dentro do Ensino, sendo esse o ponto fundamental ao se dar ênfase ao modo como a educação (uma vez pensada pelo Estado que 
assume sua tarefa criando escolas para a população) serve a interesses de mercado completamente díspares do que um dia poderá vir a ser uma educação em artes efetivamente poética. Sem me deter nas teorias do currículo que legitimam conteúdos de artes e seus transversais e sem adentrar nos sintomas que a pesquisa detecta nas escolas e nos cursos de Licenciatura, temos a sintomática das bases epistemológicas colocadas na síntese dos discursos que a fazem valer. Tal sintomatologia visa repensar as disciplinas artísticas indo ao encontro da autopoiese (DELEUZE e GUATTARI, 1992, p. 20) que cria os conceitos. Pois, são trabalhos com poesia que podem lançar outras formas para se pensar o que fazemos quando lemos e escrevemos aquilo que nos interessa e que ocupa nossas vidas.

Escritas de si, escritas endereçadas (LOPONTE, 2006; OLIVEIRA, 2012), escritas sem formulações (FARINA, 2012b), escritas que respondem não a perguntas e sim a problemas efetivos, de como se viver em sala de aula, com certos autores, repetindo práticas, vêm emergindo dentro do campo de pesquisas em torno do Ensino de Arte. Sem eliminar outras formas de se escrever sobre o que se pesquisa, um texto poético ensina uma poética, um outro tipo de pensamento e até mesmo novas estéticas, com outros e provisórios juízos. Ao nos definirmos numa linha em que tudo se movimenta e tudo se relaciona, presumo que os valores defendidos se relativizem de acordo com o que os próprios estudos vão desenvolvendo. Ao lidarmos com as transfigurações da arte e suas múltiplas definições, sempre transitórias, intrinsecamente estamos tratando mais de poiesis do que da arte como campo conhecimento configurado em linguagens específicas. Considerando a gênese poiética do que figura o pensamento, em especial o que pensa mais com imagens do que com palavras, esse pensar cria um "lugar aberto a todos os possíveis: lugar onde se cristalizam outros lugares, pontos tópicos de cruzamentos de sentidos" (RICHTER, 2012, p. 70). Mais do que um espaço polissêmico, esse lugar de ensino e pensamento que expressa os devires das artes permite que o próprio "ato pedagógico", aqui nunca desvinculado de fruir, conceber, fazer obras, seja tratado num "anelo poético-político" (PEREIRA, 2008, p. 1) entre o que extrapola as formas e exprime em atos performáticos. Trata-se de ações que expressam e imprimem modos de pensar e praticar artes nunca restritos aos conceitos que lançamos mão para falar da arte e seus ensinos. Tanto que a poética aqui tratada não se restringe a um fazer e tampouco a um dizer, mas sim a um pensar. Com ações em espaços institucionais, em aulas de 
todos os níveis, em oficinas, em ateliês particulares e outros locais de ensino e aprendizagem se pensa os devires da arte, suas múltiplas manifestações e todos modos possíveis de se ensinar artes. O que começa a ganhar evidência é a poiética de todo pensamento, a autoria no trabalho com o ensino, em especial no que diz respeito a performance do professor. Esse deixa seu papel secular, parando de somente professar para adquirir vias de atuação diversas, se tornando pesquisador, mediador, curador, autor de projetos e de ações que podem ser consideradas poéticas. A atuação desse professor, implicada em discursos, torneada pelos usos das palavras, faz com que seu proferir envolva uma prática artística, uma preparação performática, uma arte de si. Aqui, temos o "poético - em detrimento de um uso de palavra meramente instrumental, com vistas à manipulação técnica do conhecimento" (ibidem). Afirmando um trabalho com corpo e com palavras, uma prática performática, definido como poético por ser um uso mais eficaz para a ação docente, na prática educativa" (PEREIRA, 2008, p. 2).

\section{Corpo, gesto, palavra}

Em tal acepção se agrupa a compreensão de que "o gesto poético faz a realidade não ser totalizável por ser sempre da ordem das escolhas ou dos consentimentos para agir. Gesto que se revela no toque, naquilo que captura meu corpo, me toca, me afeta" (RICHTER, 2012, p. 61), existindo em seu gesto vibrações do acaso e de um pensamento não verbal, fora dos signos linguageiros, um pensamento intuitivo, epitelial, há na poética, mesmo a estritamente plástica ou pictórica, algo que arrasta o trabalho em sala de aula para além da cantilena das linguagens. Para autores de linhas críticas, fenomenológicas e mesmo para os formalistas, o poético envolve o gesto, a expressividade singular dos traços, um modo de colocar forças, via subjetividades individuais ou coletivas, no mundo extenso. Criar formas que variam a matéria encontrada no mundo, configurar mundos com formas se dá no "ato lúdico de investigar e decifrar o mundo. Ato que se elabora através de ritmos, gestos e procedimentos que independem da palavra para acontecer. No instante de figurar - plasmar traços, manchas e volumes - os pensamentos não precisam ser verbalizados, nem sequer pensados. Basta o corpo agir." (RICHTER, 2012, p. 60). O que agrupa todas as acepções poéticas dentro do ensino é a primazia do corpo e tudo o que o corpo pode, como o corpo se põe, como o corpo se exprime 
nos espaços, com outros corpos, com os materiais que encontra, com a matéria que apreende. Corpos se fazem, corpos se criam, corpos pensam: "o que faz um corpo é tecnologia que interessa à poesia" (VICTORIO FILHO, 2012, p. 151), sem autopoeises nenhum corpo se expressa.

\begin{abstract}
O corpo não espera o avanço da palavra, o corpo desespera a palavra e supera até o elogio que lhe é postulado. O corpo encarnado e encontrado no outro promete pedagogias afinadas com esse tempo, portanto, é dele, do corpo coletivo e coletivizado, que partiriam escolas, ensinos, poéticas e demais ofertas realizadoras de uma atualidade na qual a arte e a formação humana realinhariam seus significados na agudeza da pele, no abismo escatológico e no mistério transparente da conjunção (ibidem, p. 152).
\end{abstract}

Esse corpo se escreve, esse corpo é lido, esse corpo se faz docente, esse corpo se constitui discente. Poético mostra a que veio, ao invés de simplesmente "dizer". É "uma prática de contração, porque contrair quer dizer tanto afetar e ser afetado - como quem contrai um vírus ou sente as contrações do parto -, como também conjugar, conciliar, partilhar - que significa aqui, ao mesmo tempo, repartir e fazer parte" (PEREIRA, 2008, p. 2). A palavra torneia a vida dos corpos junto aos quais, em sua ação performativa, exprime-se o conjunto de elementos não verbais e não sígnicos - materializados na voz, nos gestos, no uso da palavra - que a envolvem" e que dinamizam a poética (ibidem, p. 8), a qual conduz os corpos a partilhas, conjugações, conciliações. Inerente a uma conduta poética, a ética combate a moral, os julgamentos que nos levam a proferir o que pode e o que não pode sem analisar as $n$ posições envolvidas entre os corpos, suas necessidades, mobilidades, forças. Após Foucault (2001), sabemos o quanto o corpo é uma política e como o julgamento que recai sobre os corpos os assujeita de acordo com o que o discurso, reproduzido sem bases epistemológicas, é tomado como o "certo". E o corpo, por mais que se tente, não se educa. Um corpo só pode com sua poesia, o resto tudo retira seu poder. Todavia, tudo o que pode implica a reverberação de outro corpo junto ao qual expõe seu ritmo, sua pulsão, aquilo que o leva a subverter as palavras e criar, sob superfícies ou com massas, novos mundos. Não há poesia sem o outro, sem encontro, sem relação, a tal ponto que não podemos compreender uma poética que não seja relacional. A poesia é uma política que permite os corpos resistirem aos discursos que os assujeitam a estéticas muito rígidas e a postulados morais do que é ou não arte, do que é ou não é ciência, do que é ou não é legítimo. 


\section{A poesia pode}

Afirmar uma poética na aridez dos espaços institucionais, contra o produtivismo acadêmico e critérios estreitos de julgamento, nos obriga a repensarmos métodos, crenças e palavras finais. Sua política, ao desmistificar os juízos e as racionalidades vigentes, traz como campo de disputas o cotidiano, seus devires marginais, a arte não considerada, não comercializada, a performance fora dos espaços legítimos, o menor. Num modo de pesquisar que implica "a plasticidade das práticas metodológicas de investigação do, sobre e com o cotidiano" (VICTORIO FILHO, 2012, p. 146), de modo que pesquisar se realize via encontros e performances. Menos discurso, mais corpo, relações entre ato e testemunhas, performer e público, professor e alunos, pesquisador e orientandos. "Um método que se autocria na medida em que enfrenta a diversidade de espaços e tempos que faz da vida, neste caso a escolar, acontecimentos únicos em sua multiplicidade" (ibidem). Ao privilegiar o prático, a vida marginal das salas de aulas, já temos um sintoma que diz respeito à modificação de campos de estudo, sendo nítido o deslocamento da arte sacralizada por museus e suas publicações ilustradas para manifestações na borda do sistema. Há uma ocupação poética de artes que, mesmo depois de assimiladas pelas mídias de mais destaque, atesta que não há uma produção mais legítima que outra. Ainda que algumas tenham valor de mercado enquanto muitas outras não, muitas vezes apresentam proposições autossustentáveis que não há sequer como serem vendidas.

Contra o mundo mercadológico, numa proposição outra, fora das redes de poder e visibilização, podemos procurar afetos reativos para superar a má-consciência (NIETZSCHE, 1998, p. 54), pois o valor é a graça daquilo que não tem preço e para o qual não precisamos pagar. Ninguém compra poesia, mas a vida fica inteiramente insuportável sem ela. Uma poética supõe entrega, uma exposição de si, uma abertura do pensamento, inflexões múltiplas do corpo na matéria. Um si mesmo é sempre o outro e sem alteração, o si mesmo de um professor que realmente ensina acontece no outro que com ele aprende e com quem ele aprende a ser professor, no conhecer sua matéria e pesquisar os signos que a abstraem em linguagens. De um para outro, a poesia acompanha as experiências da linguagem, uma entrega do corpo à poiesis que lhe dá poder de sair das regras de uma língua, de suas interdições, do que o corpo pode e do que, para dar sentido trágico ao próprio poema, não se pode. Como 
gesto, só se põe enquanto canto, ritmo, ditirambo, expressão daquilo que o constitui, o atravessa, o apaixona. Trata-se de uma experiência que dilacera, que expõe o que nem sempre esperamos, que lida com desesperos e "torna-se, assim, experiência do amor." (PEREIRA; MARTINI, 2008, p. 6). Não há dúvida de que a experiência poética tenha perspectivas clínicas, além das obras, reconhecidas ou não, que venham a erguê-la. Junto à pesquisa Paixão da Diferença: liberação de humores artísticos (ZORDAN, 2014), detive-me em minhas implicações com o ensino, perguntando-me, enquanto produtora de arquivos visuais, o que, afinal, a produção de pesquisa nos ensina.

Sendo tal produção de pesquisa acima de tudo textual, tomamos acepções circunscritas em campos de estudo mais amplos do que os especificados como "arte", de modo a transitar em várias poéticas advindas de todos os segmentos sociais e em diversas culturas. Os métodos recaem nas possibilidades que uma pesquisa, por si mesma, inventa. Dos diversos e instáveis usos, dos múltiplos sentidos das palavras, da brincadeira com as regras, vem a poesia. E uma poética no ensino constitui a linguagem como

Operador móbil, poroso, rarefeito que ao mesmo tempo em que determina funções e posições específicas em uma certa estrutura, também é capaz de as subverter e as desalojar, conferindo-nos nossa porção de invenção no mundo (SILVA, 2012, p. 11).

Outras linguagens, novas relações, modos de vida em que textos com outros códigos se fazem valer, ainda que todo seu valor seja ter direito à própria poesia. Sem aprofundar a jurisprudência do que pode ou não ser poesia, a questão não é avaliar se a produção poética num campo de pesquisa fere seus preceitos "científicos". O filosófico pode ser poético e o mesmo acontece quando um projeto pedagógico também é poético, cabendo salientar que sem direito a expressar um mínimo de poesia ninguém sobrevive institucionalmente. O problema, que aqui se insinua como sintoma, requer análises pormenorizadas, sendo que a presente análise genérica vem mostrar seu gradiente dentro de um campo de pesquisas, dando subsídio teórico para ações desenvolvidas em outras instâncias da pesquisa entre a educação e as artes. Enquanto prática, a poesia está longe das racionalidades e das abstrações conceituais, embora ao pesquisador seja exigido que sua linguagem se adeque a um 
modo coeso, com sentidos interligados e explicações que acompanhem problemas práticos, que requeiram experimentações concretas e quantuns de certeza.

Pensar com a linguagem e seus trocadilhos, trabalhando o nonsense ${ }^{2}$ inerente a todo discurso, possibilita a expressão de resultados de pesquisa por outros meios que não o texto dissertativo clássico. Em outros textos que compõem minha pesquisa faço a crônica de seu pathos, destacando o que impede o poético de ser validado tal qual a linguagem científica racional das academias. Em sua inaplicabilidade enquanto método ou objeto de ensino, a poesia possibilita uma escrita jamais apartada da arte. Afirma-se, assim, um modo de se ensinar ativo que se dá sem coações discursivas nos encontros formais de salas de aula e nos grupos de trabalho. Sendo uma poética no Ensino de Arte a compreensão desse como processo em aberto e aprendizagem interessada, o que aqui a pesquisa faz é prestar atenção ao sintoma do poético na escrita de si, no jogo de palavras, na invenção de métodos e nos modos de se conceber o ensino (enSIGNo). Não se trata de instituir a poesia nos programas curriculares, de criar uma racionalidade poética para o ensino das artes, tampouco defender uma tese sobre sua primazia em relação a outros aspectos da subjetivação humana. Nessa sucinta sintomática da produção ligada ao campo de discursos e textos presentes no Ensino de Arte das primeiras décadas do século XXI, é possível detectar diferentes modos e acepções de trazer a poética para práticas educacionais e outras proposições pedagógicas. E, acima de tudo, mostrar, ainda que sem detalhamentos, como a poética vem sendo sentida como elemento constituinte dentro da produção das diversas pesquisas aqui citadas.

\section{Referências}

ARISTÓTELES. Poética. São Paulo: EDIPRO, 2011.

ARNHEIM, Rudolf. Arte e percepção visual. São Paulo: EDUSP/Pioneira, 1980.

BAUDELAIRE, Charles. O Pintor da vida moderna. Belo Horizonte: Autêntica, 2010.

BOURRIAUD, Nicolas. Estética relacional. São Paulo: Martins Fontes, 2009.

DELEUZE, Gilles; GUATTARI, Felix. O que é a filosofia? São Paulo: Ed. 34, 1992.

DIAS, Belidson. A/r/tografia como metodologia e pedagogia em artes: uma introdução. In: DIAS, Belidson; IRWIN, Rita (Orgs.). Pesquisa Educacional Baseada em Arte: a/r/tografia. Santa Maria: Edufsm, 2013.

2 Para pensar o nonsense da linguagem e como opera nas relações poéticas dentro do ensino, pesquisamos A lógica do sentido, de Deleuze, juntamente com Alice no país das maravilhas, de Lewis Carrol. Cf: DELEUZE, G. Lógica do sentido. São Paulo: Perspectiva, 2000. 
FARINA, Cynthia. Experiencia estética y políticas de lo sensible en la formación de profesores. Actitud, v. 10 , p. 03-12, $2012 \mathrm{a}$.

FARINA, Cynthia. Cuerpo y conocimiento. Cartas. In: Mirela Ribeiro Meira; Ursula Rosa da Silva. (Org.). Ensino da Arte: Cultura visual, escola e cotidiano. 1ㄹed. Pelotas, RS: Editora e Gráfica Universitária UFPel, p. 117-131, 2012b.

FOUCAULT, Michel. A Arqueologia do Saber. Rio de janeiro: Forense Universitária, 1995.

FOUCAULT, Michel. A Ordem do Discurso. São Paulo: Edições Loyola, 1996.

FOUCAULT, Michel. Ditos e escritos III: Estética, literatura e pintura, música e cinema. Rio de Janeiro: Forense Universitária, 2001

HERNÁNDEZ, Fernando. A Pesquisa Baseada em Artes: propostas para repensar a pesquisa em educação. In: DIAS, Belidson; IRWIN, Rita (Orgs.). Pesquisa educacional baseada em arte. A/r/tografia, Santa Maria: EDUFSM, 2013. p. 24-55.

HERNÁNDEZ, Fernando. Cultura Visual: mudança educativa e projeto de trabalho. Porto Alegre: Artes Médicas Sul, 2000.

HERMANN, Nadja. Ética: a aprendizagem da arte de viver. Revista Educação Sociedade, Campinas, vol. 29, n. 102, p. 15-32, jan./abr. 2008. Disponível em: http://www.scielo.br/pdf/es/v29n102/a0229102.pdf. Acesso em: abr. 2012.

HOUSEN, Abigail. Validating a measure of aesthetic: development for museums and schools. LVS Review. Massachusetts College of Art, v. 2, n. 2, p. 213-237, 1992.

LARROSA, Jorge. Notas sobre a experiência e o saber da experiência. Revista Brasileira de Educação, Rio de Janeiro, n. 19, p. 20-28, jan./fev./mar./abr. 2002..

LOPONTE, Luciana G. Docência artista: arte, gênero e ético-estética docente. Educação em Revista (UFMG), Belo Horizonte/MG, n. 43, p. 35-55, 2006.

LOWENFELD, Viktor; BRITTAIN, W. Lambert. Desenvolvimento da capacidade criadora. São Paulo: Mestre Jou, 1977.

MARTINS, Mirian Celeste; PICOSQUE, Gisa. . Mediação cultural para professores andarilhos da cultura. São Paulo: Arte por escrito - Rizoma Cultural - Content Stuff, 2008. v. 1. 160 p.

MARTINS, Mirian Celeste. Professor-escavador de sentidos. In: Luiza Helena da Silva Christov; Simone Aparecida Ribeiro de Mattos. (Orgs.). Arte educação: experiências, questões e possibilidades. 1르. ed. São Paulo: Expressão e Arte, v. 1, p. 53-62, 2006.

MARTINS, Mirian Celeste Travessias para fluxos desejantes do professor-propositor. In: OLIVEIRA. Marilda de Oliveira (Org.). Arte, Educação e Cultura. Santa Maria/RS: Editora da Universidade Federal de Santa Maria, 2007, p. 349-356.

MEIRA, Marly. Filosofia da criação: reflexões sobre o sentido do sensível. Porto Alegre: Mediação, 2003.

NIETZSCHE, Friedrich. Genealogia da moral: uma polêmica. Trad. Paulo César de Souza. São Paulo: Companhia das Letras, 1998.

NIETZSCHE, Friedrich. Ecce homo: como alguém se torna o que é. Trad. Paulo César de Souza. São Paulo: Companhia das Letras, 1995.

OLIVEIRA, Marilda de Oliveira. Contribuições da perspectiva metodológica "Investigação Baseada nas Artes" e da A/r/t/tografia para as pesquisas em Educação. In: 36 ${ }^{\mathrm{a}}$ Reunião Anual da ANPED, 2013, Goiânia. Anais... Goiânia, 2013. Disponível em: http://36reuniao.anped.org.br/pdfs_trabalhos_aprovados/gt24_trabalhos_pdfs/gt24_2792_texto.pdf

OLIVEIRA, Marilda de Oliveira. Três notas sobre a formação inicial em artes visuais: a perspectiva da cultura visual, o endereçamento e os diários de aula. Instrumento (Juiz de Fora), v. 14, p. 255-262, 2012.

OSTROWER, Fayga. Universos da arte. Rio de Janeiro: Campus, 1983.

OSTROWER, Fayga. Acasos e criação artística. Rio de Janeiro: Campus, 1986.

PARSONS, Michael J. Compreender a arte. Lisboa: Presença, 1992 
PEREIRA, M. de Andrade. Pedagogia da Performance: do uso poético da palavra na prática educativa. In: 31르 Reunião Anual da ANPED, 2008, Caxambu. Anais... Caxambu, 2008.

PEREIRA, Marcos Villela. O limiar da experiência estética: contribuições para entender um percurso de subjetivação. Pro-Posições (UNICAMP. Impresso), v. 23, p. 183-195, 2012.

PILLAR, Analice Dutra. O papel do professor nas aulas de artes. Porto Alegre: FACED/UFRGS, 1986.

PILLAR, Analice Dutra. Desenho e construção de conhecimento na criança. Porto Alegre: Artes Médicas, 1996.

PILLAR, Analice Dutra. Criança e televisão: leitura de imagens. Porto Alegre, Mediação, 2001.

READ, Herbert. A educação pela arte. São Paulo: Martins Fontes, 1982.

RICHTER, Sandra Simonis. Experiência poética e linguagem plástica na educação. In: Mirela Ribeiro Meira; Ursula Rosa da Silva. (Orgs.). Ensino da arte: cultura visual, escola e cotidiano. $1^{\underline{a}}$ ed. Pelotas: Editora e Gráfica Universitária, 2012. p. 57-79.

RICHTER, Sandra Simonis. Criança e pintura: ação e paixão do conhecer. Porto Alegre: Mediação, 2004.

ROSSI, Maria Helena Wagner. Imagens que falam: leitura da arte na escola. Porto Alegre: Mediação, 2003.

ROSSI, Maria Helena Wagner. Reflexões sobre a mediação estético-visual: como estimular o encontro com a obra. In: Encontro Internacional Diálogos em educação, Museu e Arte, 2010, Pinacoteca do estado de São Paulo, São Paulo. Anais... São Paulo, 2010.

SILVA, T. R. S. . Notas sobre a criação - elementos para repensar o espaço escolar. In: 35a Reunião Anual da ANPED, 2012, Porto de Galinhas/PE. Anais... Porto de Galinhas/PE, 2012.

SMITH, Peter. Franz Cizek: the patriarch. Art Education, 38, n. 2, p. 28-31, 1985.

TOURINHO, Irene; MARTINS, Raimundo;HERNÁNDEZ, Fernando. Aprender história do ensino de arte através da realização de histórias de vida. Extensão e Cultura (UFG), v. 2, p. 110-119, 2006.

VAZ, T. Encontros e esperas de uma professora em percurso. 2013. 86f. Dissertação (Mestrado em Educação) - Programa de Pós-graduação em Educação da Universidade Federal de Santa Maria, Santa Maria. 2013.

VICTORIO FILHO, Aldo. Corpo escola: currículo vibrátil e pedagogia da carne. Currículo sem Fronteiras, v. 12, p. 143-157, 2012.

VICTORIO FILHO, Aldo. Ensino da Arte hoje: desafios, sentidos e sintonias. In: $31{ }^{\text {a }}$ Reunião Anual da ANPED, 2008, Caxambu. Anais... Caxambu, 2008.

ZORDAN, Paola. Paixões da Diferença: liberação de humores artísticos (Relatório Final de Pesquisa). Porto Alegre: FACED/UFRGS, 2014. 331f.

\section{Paola Basso Menna Barreto Gomes Zordan}

Professora do Programa de Pós-Graduação em Educação da Universidade Federal do Rio Grande do Sul, (UFRGS). Articuladora do M.A.L.H. A., Movimento Apaixonando pela Liberação de Humores Artísticos, cria intervenções em espaços públicos e institucionais. Trabalha com performances, escultura social e micropolíticas. Doutora e Mestre em educação pela UFRGS, faz parte da Linha de Pesquisa Filosofia da Diferença e Educação, do grupo de pesquisa DIF: artistagens, fabulações e variações, desenvolvendo temas que envolvem historiografia da arte, formação de professores e esquizoanálise. Licenciada em Educação Artística, bacharel em Desenho, foi professora de Arte em escolas da rede de ensino em Porto Alegre.

E-mail: paola.zordan@gmail.com

Currículo: http://lattes.cnpq.br/4035205657093564 